Academic Platform Journal of Engineering and Science

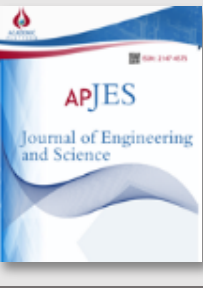

\title{
Armut (Pirus communis L.) Posasının Bazı Kalite Değerleri Açısından Uygun Kurutma Sıcaklığının Belirlenmesi
}

\author{
${ }^{* 1}$ Hakan Polatcı, ${ }^{1}$ Muhammed Taşova, ${ }^{2}$ Onur Saraçoğlu \\ ${ }^{1}$ Tokat Gaziosmanpaşa Üniversitesi, Ziraat Fakültesi, Biyosistem Mühendisliği Bölümü, hakan.polatci@gop.edu.tr, \\ muhammed.tasova@gop.edu.tr, \\ ${ }^{2}$ Tokat Gaziosmanpaşa Üniversitesi, Ziraat Fakültesi, Bahçe Bitkileri Bölümü, onur.saracoglu@ gop.edu.tr,
}

Araştırma Makalesi

Geliş Tarihi: 11.02.2019

Kabul Tarihi: 14.09 .2020

$\ddot{O} \mathbf{z}$

Meyve posaları içerdiği besin değerlerinden dolayı, gübre olarak kullanımının yanında hayvan yemi olarak da kullanımı çok yaygındır. Kuşburnu, portakal, havuç, turp gibi birçok meyve sebze atıkları posa olarak değerlendirilmektedir. Çalışmada kapsamında, kabin tip bir kurutucu ile 60,65 ve $70{ }^{\circ} \mathrm{C}$ sicaklık değerlerinde kurutularak, armut posasının ortalama kuruma süreleri, renk, asitlik (pH), suda çözünebilir kuru madde (SÇKM) ve titrede edilebilir asitlik (T.A.) değerleri belirlenmiştir. Ürün, kurutma havası sıcaklıklarında yaş baza (y.b.) göre \% 10-13 nem seviyelerine kadar kurutulmuştur. Sicaklık değerlerine göre ortalama kuruma süreleri sırasıyla; 24, 21 ve 12 saat olarak tespit edilmiştir. Kurutma işlemi esnasında uzaklaşan nem oranları kurutma eşitliklerinde işlenerek eğrileri oluşturulmuş ve en iyi tahmin eden modelin Midilli-Küçük olduğu belirlenmiştir. Kurutulan ürünlere ait ölçülen renk değerleri tazeye göre kıyaslanarak istatistiki açıdan en uygun kurutma havası sıcaklığı belirlenmiştir. Hesaplanarak belirlenen renk kriterlerinden olan, kroma değerleri tazeye göre kıyaslandığında en uygun değer $65^{\circ} \mathrm{C}$ kurutma sıcaklığında belirlenmiştir. Kurutulan ürünlerin pomolojik özellikleri hakkında önemli bilgiler veren pH, SÇKM, ve T.A. özelliklerine ait en yüksek ve en düşük ortalama değerler ise sırasıyla; 3.65-3.44, 2.70-2.33, 1.68-1.10 olarak belirlenmiştir.

Anahtar Kelimeler: Armut posası, konvektif kurutma, renk, kimyasal analiz

\section{Determination of Appropriate Drying Temperature in Terms of Some Quality Values of Pear (Pirus communis L.)}

\author{
${ }^{* 1}$ Hakan Polatc1, ${ }^{1}$ Muhammed Taşova, ${ }^{2}$ Onur Saraçoğlu \\ ${ }^{1}$ Tokat Gaziosmanpaşa Unıversity, Faculty of Agriculture, Bısystem Engineering Deparment, hakan.polatci@gop.edu.tr, \\ muhammed.tasova@gop.edu.tr \\ ${ }^{2}$ Tokat Gaziosmanpaşa Unıversity, Faculty of Agriculture, Garden Plants Deparment, onur.saracoglu@ gop.edu.tr
}

\begin{abstract}
Due to the nutritional value of fruit pulp, it is very common to use it as animal feed besides fertilizer. Many fruit and vegetable wastes such as rosehip, oranges, carrots and radishes are considered to be pulp. Within the scope of the study, average drying time of pear pulp, color, acidity $(\mathrm{pH})$, water soluble dry matter (WSDM) and titratable acidity (T.A.) values were determined by drying in temperatures values of 60,65 and $70{ }^{\circ} \mathrm{C}$ with a cabinet type dryer. The product was dried to $10-13 \%$ moisture levels at the drying air temperatures according to the age base (w.b.). Average drying times according to temperature values are as follows; 24, 21 and 12 hours. During the drying period, the moisture values in the unit time away from the product were processed in the thin layer drying models and drying curves were formed and the best estimating mathematical model was determined as the Midilli-Küçük. The measured color values of dried products were compared according to freshness and the most suitable drying air temperature was determined statistically. When the chroma values were compared to freshness, the most suitable value was determined at $65{ }^{\circ} \mathrm{C}$ drying temperature. The $\mathrm{pH}$, WSDM and T.A. the highest and lowest average values are; 3.65-3.44, 2.702.33, 1.68-1.10.
\end{abstract}

*Sorumlu Yazar: Tokat Gaziosmanpaşa Üniversitesi, Ziraat Fakültesi, Biyosistem Mühendisliği Bölümü, hakan.polatci@ gop.edu.tr, 0541496 6664 
Keywords: Pear pomace, convective drying, color, chemical

\section{GÍRİs}

Armut (Pirus communis L.) gülgillerden olup [1], ilk olarak Asya kıtasında yetiştirilerek tüm dünyaya yayılmış olan bir meyve türüdür [2]. Armut meyvesi dünyada elma ve üzümden sonra en fazla yetiştirilen meyvedir. Dünya üzerinde 5000 'den fazla armut çeşidi bulunduğu ve bunların yaklaşık 640 tanesi ülkemizde yetişmektedir [3-6]. Taze armudun bünyesinde; Vitaminler, fenolik bileşikler, organik asitler, yağ asitleri ve büyük miktarda da su bulunmaktadır [7-11].

Armudun meyve suyu şeklinde tüketimi, çay ve kahve gibi kafein içerikli içeceklere göre daha doğal olmasından dolayı son yıllarda önemli seviyede artış göstermektedir [12-13]. Armut, bünyesinde barındırdığı ortalama \% 75-80 civarında su oranı ile meyve suyu üretiminde yaygın bir şekilde kullanılmaktadır. Meyve suyu üretiminde oluşan meyve posaları ise yüksek oranda lif içermektedir. Bu nedenle, meyve posaları genellikle hayvan beslemesinde yaygın olarak kullanılmaktadır. Bunun için yıl boyu bozulmadan kullanabilmek için meyve suyu üretimi sonrasında oluşan posalar uygun yöntemlerle kurutularak depolanmalıdır. Aksi takdirde hem kötü kokular oluşur hem de besin değerleri hızla parçalanıp kaybolur.

Kurutma; Yaş meyve posalarının güvenli bir şekilde saklanabilmesi için uygulanan en yaygın metotlardan biridir. Kurutma işlemi ile üründeki nemin büyük bir kısmı uzaklaştırılmakta ve ürün su aktivitesi değerinin düşürülüp, mikroorganizma faaliyetleri engellenmektedir [14]. Meyve ve posalarına ait nem seviyelerinin düşürülmesi için genellikle güneş, gölge ortamları ile yapay kurutucular kullanılmaktadır. Doğal kurutma yönteminde, kurutma süresinin uzun olmakta ve besin değerleri çok fazla kaybolmaktadır. Bunun yanında, zehirli gaz ve böceklerin ürünlerin üzerine konarak sağlık açısından uygun olmayan durumlar oluşturmaktadır.

Meyve posayla ilgili literatür de; [15]' deki çalışmada, sprey kurutma yöntemini kullanarak kuruttuğu Barbados kirazı posasının fiziksel özelliklerini belirlemiştir. [16]' da ki çalışmaya göre, kurutulan üzüm posası örneklerine katılan farklı maddelerin neticesinde posanın aneorabik ve bazı diğer kriterlere olan etkilerini belirlemiştir. [17]' de belirtilen çalışmaya göre, farklı kurutma şartlarında kuruttuğu kayısı posasının sosis üretiminde kullanım olanaklarını incelemiştir. [18]' de ifade edilen çalışmada, üç farklı kurutma sicaklığı kullanarak kuruttuğu zeytin posasının kuruma karakteristiklerini belirlemişlerdir. [19]' da ki belirtilen çalışmada, akışkan yataklı bir kurutucuda zeytin posasını kurutarak ürünün kuruma kinetiği değişimini incelemiştir. [20]' de belirtilen çalışmaya göre, elma, kayısı ve şeftali posalarının bazı fiziksel ve kimyasal özelliklerini araştırmışlardır. Literatür taraması sonucunda bazı meyve posaları üzerine yapılan kurutma çalışmalarının var olduğu ancak armut posasının kurutma sıcaklıkları altında renk ve bazı kimyasal özellikler açısından uygun kurutma sıcaklığının belirlenmesi konusunda bir çalışmaya rastlanılmamıştır.

$\mathrm{Bu}$ çalışmada, kabin tip bir kurutucu ile kurutulan armut posalarının kurutma sıcaklıkları açısından en uygun kuruma süresi, renk ve bazı kimyasal özellikleri belirlenerek literatüre katkı sağlanması amaçlanmıştır.

\section{MATERYAL VE YÖNTEM}

\subsection{Kurutulacak ürün}

Armut posas1, meyve ve süt ürünleri üretim işletmesinden temin edildikten sonra kurutma laboratuvarına getirilmiştir. İşlemler sonlanana kadar posalar $+4 \pm 0.5^{\circ} \mathrm{C}$ sıcaklıktaki bir buzdolabında muhafaza edilmiştir.

\subsection{Nem tayini}

Yaş meyve posaları kurutulmadan önce nem içerikleri belirlenmiştir. Nem tayini işleminde ortalama 70' er g olmak üzere dörder tekerrür olarak yapılmıştır. İşlem $70{ }^{\circ} \mathrm{C}$ sıcaklığa sahip bir firında, ürünler belli süre aralıklarında ağırlıkları ölçülerek sabit değere kadar bekletilmiştir [21].

\subsection{Kurutma işlemi}

İşlemler kabin tip bir konvektif kurutucuda 60,65 ve $70{ }^{\circ} \mathrm{C}$ sıcaklıklarda gerçekleştirilmiştir. $3^{\prime}$ er tekerrür halinde yapılan işlemlerde ortalama $70 \pm 0.5 \mathrm{~g}$ ürün kullanılmıştır. Kurutulan ürünler ara ara belirli sürelerde $\% 1$ hassasiyete sahip bir terazide tartılarak su içeriği \% 10-13 seviyesine düşene kadar işlemler devam etmiştir [22-23].

\subsection{Etüv kurutucu}

Kurutma işleminde kullanılan konvektif kurutucu Şimşek Laborteknik marka olup ST-120 tip model kullanılmıştır. Kurutma sıcaklığını istenilen sıcaklığa ayarlayabilmek için, üzerinde bulunan PID kontrol denetliyiciler kullanılarak 30$250{ }^{\circ} \mathrm{C}$ sicaklığa kadar ayarlanabilme özelliği bulunmaktadır.

\subsection{Renk ölçümü}

Tarımsal ve gıda ürünlerinin en önemli kalite değerleri kriterlerden birisi de renk özelliğidir. Ürünlerde meydana gelen olumsuz renk değişimleri, ürünlerin market değerini önemli seviyede olumsuz etkilemektedir [24-25]. Taze ve kurutulmuş armut posalarının renk ölçümlerinde Minolta 
marka CR300 modeli renk ölçer kullanılmıştır. Renk ölçer ile posasnın Hunter Lab Chromameter değerleri ölçülmüştür.

Ölçülen değerlerden L posasının parlaklığını temsil ederken 0 ile 100 arasında değişmektedir. a değeri posanın kırmızı ve yeşil, b değeri ise sarı ve mavi renkleri temsil etmektedir [26]. Ölçülen L, a ve değerleri tek başlarına bir anlam ifade etmezken bu değerler kullanılarak hesaplanan kroma değeri, hue açısı, toplam renk farklılığı ve kahverengileşme indeks değerleri hesaplanmıştır.

Kroma değeri: Ürün renginin tonunu ifade etmektedir. [27]' de belirtilen yönteme göre, kroma değeri 1 nolu eşitlik kullanarak hesaplandığını ifade etmişlerdir.

$$
\mathrm{C}=\left(\mathrm{a}^{2}+\mathrm{b}^{2}\right)^{1 / 2}
$$

Hue değeri: Hue renk açısı değeri $360^{\circ}$ 'lik bir renk gradyantında her açıya karşılık gelen renklerin neler olduğunu ifade etmektedir.

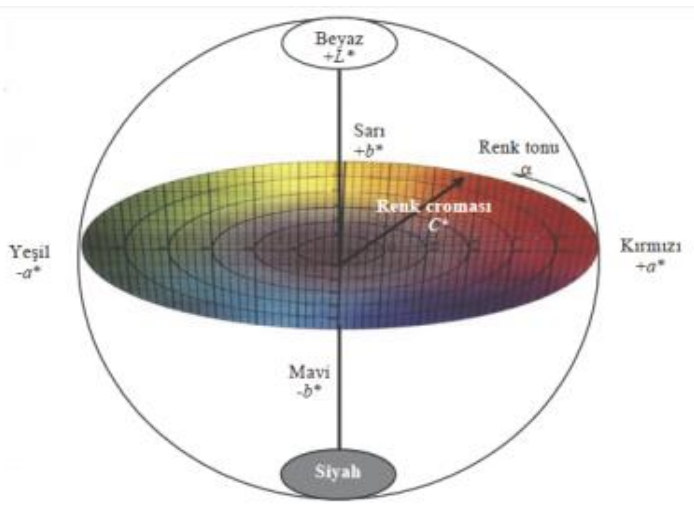

Şekil 1. Hue açısının renk radyantı [28].

$0^{\circ} \mathrm{k}$ rrmızı, $90^{\circ} \mathrm{sar}$, $180^{\circ}$ yeşil ve $270^{\circ}$ ise ürünün mavi renkte olduğunu bu açı değerlerinin aralarına karşılık gelen kısımlarda ara renklerin oluştuğunu ifade edilmiştir (Şekil 1). [29-30]' yapılan çalışmalara göre, hue renk açısı değerinin 2 nolu eşitlik kullanılarak hesaplandığını ifade etmişlerdir.

$$
\mathrm{h}^{\circ}=\tan ^{-1}\left(\frac{\mathrm{b}}{\mathrm{a}}\right)
$$

Toplam renk farklılık değeri: Taze ürünün ölçülen renk değerleri ile kurutulduktan sonraki renk değerleri arasındaki değişimi ifade etmek için kullanılmaktadır. [28]' de belirtilen yönteme göre, toplam renk farklılık değerinin 3 nolu eşitlik kullanılarak hesaplandığını ifade etmişlerdir.

$$
\Delta \mathrm{E}=\sqrt{\left(\mathrm{L}_{\mathrm{t}}-\mathrm{L}_{\mathrm{k}}\right)^{2}+\left(\mathrm{a}_{\mathrm{t}}-\mathrm{a}_{\mathrm{k}}\right)^{2}+\left(\mathrm{b}_{\mathrm{t}}-\mathrm{b}_{\mathrm{k}}\right)^{2}}
$$

Eşitlikte $L_{t}, a_{t}$ ve $b_{t}$ değerlerinin sırasıyla taze ürünün parlaklık, kırımızı-yeşillik ve sarılık-mavilik renk değerlerini ifade ederken, $L_{k}, a_{k} v e b_{k}$ değerleri ise kuru ürüne ait renk değerlerini ifade etmektedir.

Kahverengileşme indeksi: Ürünün kahverengileşme indeks değerini simgeleyen " BI " ile " $\mathrm{x}$ " katsayısı değerleri ise ürünün kuruma sonrası kahverengileşme değerini ifade etmektedir. [31]' ifade edilen çalışmaya göre, kahverengileşme indeks değeri ile bu değerin hesaplanmasında kullanılan "x" katsayısının 6 ve 7 nolu eşitlikler kullanılarak hesaplandığını göstermişlerdir.

$$
\begin{aligned}
& \mathrm{BI}=\frac{[100(\mathrm{x}-0,31)]}{0,17} \\
& \mathrm{X}=\frac{\mathrm{a}+(1,75 \mathrm{xL})}{[(5,645 \mathrm{xL})+(\mathrm{a}-(3,012 \mathrm{xb}))]}
\end{aligned}
$$

\subsection{Kuruma modeli}

Armut posasında süreye göre uzaklaşan su oranı değeri 8 nolu eşitlik kullanılarak tespit edilmiştir.

$$
\mathrm{ANO}=\frac{\mathrm{M}-\mathrm{M}_{\mathrm{e}}}{\mathrm{M}_{0}-\mathrm{M}_{\mathrm{e}}}
$$

ANO: Posadan uzaklaşabilen su miktarı

M: Posa içerisinde bulunan o andaki su miktarı

$\mathrm{M}_{\mathrm{e}}$ : Posanın o şartlardaki denge nemi

$\mathrm{M}_{\mathrm{o}}$ Posanın su içeriği

Armut posasının kuruması esnasında uzaklaşan su oranlarına ait değerleri modellemek için literatürde çok sık kullanılan Page, Midilli-Küçük ve Yağcıoğlu eşitliklerinde işlenmiştir. Kullanılan modellere ait eşitlikler Tablo 1' de verilmiştir.

Tablo 1. İnce tabakalı matematiksel kuruma modelleri

\begin{tabular}{ccc}
\hline No & Model ismi & Eşitlik \\
\hline 1 & Page & MR $=\exp \left(-\mathrm{h} \cdot\left(\mathrm{t}^{\mathrm{j}}\right)\right)$ \\
2 & Midilli küçük & MR $=$ h.exp $\left(-\mathrm{j} .\left(\mathrm{t}^{\mathrm{k}}\right)\right)+(1 . \mathrm{t})$ \\
3 & Yağcioğlu & MR $=\mathrm{k} \cdot \exp (-\mathrm{h} \cdot \mathrm{t})+\mathrm{j}$ \\
\hline
\end{tabular}




\subsection{Kimyasal analizler}

Taze ve kurutulmuş armut posalarının pH, T.A. ve SÇKM değerleri belirlenerek tazeye göre en uygun kurutma havası sıcaklık değerleri belirlenmiştir. Yapılan analizler;

pH: Her bir sicaklıkta kurutulan meyve posaları belirli oranlarda sulandırıldıktan sonra laboratuvar koşullarında $\mathrm{pH}$ metre ile okuma yapılmıştır.

Titre edilebilir asit oranı (\%): Sulandırılmış taze ve kurutulmuş armut posalarından, $5 \mathrm{~mL}$ alınarak $0.1 \mathrm{~N} \mathrm{NaOH}$ çözeltisi ile ve bir pH metre yardımıyla titre edilmiştir. Titrasyon işlemi 3 paralelli olarak yapılıp, titrasyon sonuçlarının ortalamasından titre edilebilir asit miktarı \% olarak saptanmıştır.
Suda çözünebilir kuru madde (SÇKM) (\%): Taze ve kurutulmuş armut posalarından rasgele seçilen örnekler pres ile suları çıkarılıp, suda çözünebilir kuru madde miktarları portatif hassas dijital $( \pm 0.01)$ refraktometre ile okunmuştur [32-33].

\section{BULGULAR VE TARTIŞMA}

\subsection{Kuruma değerleri}

Kurutulan armut posasının su içeriği ortalama \% 77.65 olarak belirlenmiştir. Ürünün kurutma şartları altındaki ortalama kuruma süreleri belirlenmiş ve kurutma sıcaklığının kuruma değerlerini değiştirdiği ve sıcaklığın yükselmesiyle kuruma değerlerinin azaldığı görülmüştür (Tablo 2).

Tablo 2. Armut posasının kuruma performans değerleri

\begin{tabular}{ccc}
\hline Kurutma sıcaklıkları & $\begin{array}{c}\text { Ortalama son nem } \\
\text { değerleri } \\
(\%)\end{array}$ & $\begin{array}{c}\text { Kuruma süreleri } \\
\text { (saat) }\end{array}$ \\
\hline $60^{\circ} \mathrm{C}$ & $\% 10,15$ & 24 \\
$65^{\circ} \mathrm{C}$ & $\% 10,05$ & 21 \\
$70^{\circ} \mathrm{C}$ & $\% 11,00$ & 12 \\
\hline
\end{tabular}

[34]' de belirtilen çalışmaya göre, kuzukulağı bitkisini 40, 50 ve $60{ }^{\circ} \mathrm{C}$ sıcaklık ve $1 \mathrm{~m} / \mathrm{s}-2 \mathrm{~m} / \mathrm{s}$ hava hızları altında yaptığ kurutma çalışmasında sıcaklık ve hava hızının artmasıyla ürünün kuruma süresinin azalttığını ifade etmiştir. Benzer bulguları, [35-38]' de yapılan çalışmalarda tespit etmişlerdir.
3.2. Kuruma modellerine ait katsayılar, " $R^{2 "}$ ve "p" değerleri

Armut posasının kuruması esnasında uzaklaşan su oranlarına ait değerleri modellemek için kuruma eğrileri belirlenmiştir. Modellere ait katsayılar, güvenilirlik değerleri ve tahmin yakınlığını ifade eden $\mathrm{R}^{2}$ değerleri Tablo 3., 4. ve 5.' te verilmiştir.

Tablo 3. Page modeline ait bazı değerler

\begin{tabular}{ccccc}
\hline Kurutma sicaklıkları & $\mathbf{k}$ & $\mathbf{h}$ & $\mathbf{R}^{\mathbf{2}}$ & $\mathbf{p}$ \\
\hline $60^{\circ} \mathrm{C}$ & 0,0340 & 1,4120 & 0,9949 & $<0,0001$ \\
$65^{\circ} \mathrm{C}$ & 0,0454 & 1,3819 & 0,9954 & $<0,0001$ \\
$70^{\circ} \mathrm{C}$ & 0,1095 & 1,2796 & 0,9958 & $<0,0001$ \\
\hline
\end{tabular}

Tablo 4. Midilli-Küçük modeline ait bazı değerler

\begin{tabular}{ccccccc}
\hline $\begin{array}{c}\text { Kurutma } \\
\text { sicaklıkları }\end{array}$ & $\mathbf{k}$ & $\mathbf{h}$ & $\mathbf{j}$ & $\mathbf{m}$ & $\mathbf{R}^{2}$ & $\mathbf{p}$ \\
\hline $60^{\circ} \mathrm{C}$ & 1,2450 & 0,9962 & 0,0397 & $-0,0057$ & 0,9990 & $<0,0001$ \\
$65^{\circ} \mathrm{C}$ & 1,2175 & 0,9969 & 0,0523 & $-0,0061$ & 0,9993 & $<0,0001$ \\
$70{ }^{\circ} \mathrm{C}$ & 1,1236 & 0,9993 & 0,1175 & $-0,0099$ & 0,9991 & $<0,0001$ \\
\hline
\end{tabular}


Tablo 5. Yağcıoğlu modeline ait bazı değerler

\begin{tabular}{cccccc}
\hline $\begin{array}{c}\text { Kurutma } \\
\text { sicaklıkları }\end{array}$ & $\mathbf{k}$ & $\mathbf{h}$ & $\mathbf{j}$ & $\mathbf{R}^{2}$ & $\mathbf{p}$ \\
\hline $60^{\circ} \mathrm{C}$ & 1,5948 & 0,0446 & $-0,5740$ & 0,9979 & $<0,0001$ \\
$65^{\circ} \mathrm{C}$ & 1,5025 & 0,0563 & $-0,4835$ & 0,9983 & $<0,0001$ \\
$70^{\circ} \mathrm{C}$ & 1,3564 & 0,1088 & $-0,3452$ & 0,9988 & $<0,0001$ \\
\hline
\end{tabular}

Page modeli kuruma eğrilerini en iyi $70{ }^{\circ} \mathrm{C}$ kurutma havası sıcaklığında tahmin ederken, Midilli-Küçük modeli, $65{ }^{\circ} \mathrm{C}$ kurutma havası sıcaklığında, Yağcığlu modeli ise kuruma eğrilerini en iyi $70{ }^{\circ} \mathrm{C}$ kurutma havası sıcaklığında tahmin etmiştir. Tahmin edilen tüm kuruma eğrilerinde modellerin güvenilirlik değerlerinin $\mathrm{p}<0.05$ olduğu yani kullanımlarının uygun bulunmuştur. Uygulanan modeller içerisinde ise en iyi tahmin edenin Midilli-Küçük olduğu tespit edilmiştir.

\subsection{Renk değerleri}

Kurutma materyaline ait renk ölçerle belirlenen renk değerleri kullanılarak ürünün rengi hakkında daha fazla bilgi veren hesaplanan değerleri hesaplanmıştır (Tablo 6).

Tablo 6. Ölçülen renk değerleri ve Duncan test sonuçları

\begin{tabular}{cccc}
\hline Kurutma sıcaklıkları & $\mathbf{L}$ & $\mathbf{a}$ & $\mathbf{b}$ \\
\hline Taze & $41,61^{\mathrm{a}}$ & $5,08^{\mathrm{b}}$ & $17,37^{\mathrm{c}}$ \\
$60^{\circ} \mathrm{C}$ & $38,99^{\mathrm{a}}$ & $8,54^{\mathrm{a}}$ & $28,42^{\mathrm{a}}$ \\
$65^{\circ} \mathrm{C}$ & $31,93^{\mathrm{b}}$ & $8,72^{\mathrm{a}}$ & $23,24^{\mathrm{b}}$ \\
$70^{\circ} \mathrm{C}$ & $34,09^{\mathrm{b}}$ & $8,54^{\mathrm{a}}$ & $26,78^{\mathrm{a}}$ \\
\hline
\end{tabular}

* Duncan testleri $(p<0.05)$ değerine göre yapılmıştır.

Tablo 6 'de renk değerlerine ait duncan test sonuçları verilmiştir. Polatcı ve Tarhan (2009), farklı kurutma şartlarının reyhan yapraklarının renk değerlerine olan etkisini istatistiksel olarak farkı ifade edebilmek için duncan testini kullanmışlardır. Tablo 7. 'da ise taze kurutulmuş posaya ait hesaplanan ikincil renk değerleri verilmiştir.

Tablo 7. Hesaplanan ortalama renk değerleri

\begin{tabular}{cccccc}
\hline Kurutma sıcaklıkları & $\mathbf{C}$ & $\mathbf{H}^{\circ}$ & $\boldsymbol{\Delta E}$ & $\mathbf{x}$ & $\mathbf{B I}$ \\
\hline Taze & 18,10 & 73.71 & - & - & - \\
$60^{\circ} \mathrm{C}$ & 29,68 & 73,28 & 29,17 & 0.54 & 133.34 \\
$65^{\circ} \mathrm{C}$ & 24,82 & 69.44 & 23.92 & 0.54 & 137.05 \\
$70^{\circ} \mathrm{C}$ & 28,10 & 72.32 & 26.76 & 0.57 & 151.03 \\
\hline
\end{tabular}

Tablo 6 'te taze posasının parlaklık (L) değerine göre kurutma havası sıcaklıklarında belirlenen tüm $\mathrm{L}$ değerleri uzaklaşmıştır. Tazeye göre parlaklık değeri en az $65{ }^{\circ} \mathrm{C}$ kurutma havası sıcaklığında korunduğu belirlenirken en az fazla korunmanın ise $60{ }^{\circ} \mathrm{C}$ kurutma havası sicaklığında tespit edilmiştir. Bunun sebebinin ürünün kurutma sıcaklığının artmasıyla beraber düşük sıcaklık değerlerine göre daha hızlı kuruyarak renk değerlerini koruyamadığını ve düşük sıcaklık değerinde ise ürün uzun süre sıcaklığa maruz kaldığından dolayı parlaklık değerini muhafaza edemediği düşünülmektedir. Taze ürüne göre kurutulmuş ürünlerin kırmızılık değerlerinin tümünde bir artmanın olduğu ve kurutma sıcaklıklarında belirlenen kırmızılık değerleri arasında ise istatistiksel olarak önemli bir farklılık oluşmamıştır. Taze ürüne göre sarılık değerinin en az 60 ve
$70{ }^{\circ} \mathrm{C}$ kurutma havası sıcaklığında korunduğu belirlenirken en fazla korunmanın ise $65^{\circ} \mathrm{C}$ kurutma havası sıcaklığında belirlenmiştir.

Tablo 7 'ya göre piyasa değeri açısından önemli bir kıriter olan kroma değeri açısından taze ürüne göre kurutulmuş ürünler kıyaslandığında tüm kurutma şartlarında kroma değerleri artmıştır. Ancak taze ürüne en yakın kroma değeri $65{ }^{\circ} \mathrm{C}$ kurutma havası sicaklığında yapılan kurutma işleminde belirlenmiştir.

\subsection{Kimyasal analiz değerleri}

Taze ve kurutulmuş armut posasının pH, SÇKM ve T.A. değerleri belirlenmiştir (Tablo 8). 
Tablo 8. Belirlenen ortalama pH, S.Ç.K.M ve T.A. değerleri ile Duncan test sonuçları

\begin{tabular}{ccccc}
\hline \multirow{2}{*}{ Kimyasal Özellikler } & \multicolumn{3}{c}{ Kurutma sıcaklıkları } \\
\cline { 2 - 5 } & Taze & $60^{\circ} \mathrm{C}$ & $65^{\circ} \mathrm{C}$ & $70^{\circ} \mathrm{C}$ \\
\cline { 2 - 5 } SÇKM & $2.47^{\mathrm{b}}$ & $2.33^{\mathrm{c}}$ & $2.33^{\mathrm{c}}$ & $2.70^{\mathrm{a}}$ \\
pH & $3.68^{\mathrm{a}}$ & $3.44^{\mathrm{b}}$ & $3.50^{\mathrm{b}}$ & $3.65^{\mathrm{a}}$ \\
T.A. & $1.16^{\mathrm{b}}$ & $1.68^{\mathrm{a}}$ & $1.23^{\mathrm{b}}$ & $1.10^{\mathrm{b}}$ \\
\hline
\end{tabular}

Taze posaya göre kurutulan ürünlerin SÇKM değerlerinde artışın olduğu belirlenmiştir. Kurutulan ürünler içerisinde en yüksek SÇKM değerinin 26.58 ile $70{ }^{\circ} \mathrm{C}$ kurutma havası sicaklığında belirlenmiştir. Taze ve kurutulmuş ürünlerin $\mathrm{pH}$ değerleri açısından incelendiğinde aralarında önemli bir değişikliğin olmadığı ve taze posaya göre en yakın $\mathrm{pH}$ değerinin $65^{\circ} \mathrm{C}$ kurutma havası sıcaklığında belirlenmiştir. Titrde edilebilir asitlik değeri açısından taze ve kurutulmuş ürünler arasında bir artışın olduğu ve tazeye en yakın T.A. değerinin $65^{\circ} \mathrm{C}$ kurutma havası sıcaklığında belirlenmiștir.

\section{SONUÇ}

Armut posası içerdiği hem besin değerleri hem de etken maddeleri açısından hayvan beslemesinde kullanılan önemli bir meyve posasıdır. Çalışmada, kabin tip bir konvektif kurutucu ile kurutulan armut posasına ait kuruma, renk, kuruma eğrileri, $\mathrm{pH}, \mathrm{SÇKM}$ ve T.A. değerleri belirlenmiş ve bazı sonuçlara ulaşılmıştır;

1) Kurutma havası sıcaklık değerlerinin ürünün kurumasında etkili bir kriter olduğu ve sıcaklık değerinin artmasıyla kuruma süresinin azaldığı belirlenmiştir.

2) En uzun kurutma işleminin, $60{ }^{\circ} \mathrm{C}$ kurutma havası sıcaklığında 24 saat sürdüğü belirlenirken, en kısa kurutma işlemi ise, $70^{\circ} \mathrm{C}$ kurutma havası sıcaklığında 12 saat sürdüğü belirlenmiştir.

3) Uygulanan ince tabakalı kurutma modelleri içerisinde en yüksek $\mathrm{R}^{2}$ değeri Midilli-Küçük modeli olduğu belirlenmiştir. Bu nedenle Midilli-Küçük modeli uygulanan ince tabakalı matematiksel kurutma eşitlikleri arasında kuruma eğrisini en iyi tahmin eden model olarak belirlenmiştir.

4) Ürünün piyasa değeri açısından önemli bir renk kriteri olan kroma değeri açısından, ürün rengi tazeye göre, $65^{\circ} \mathrm{C}$ kurutma havası sıcaklığında kurutulmasının daha uygun olduğu tespit edilmiştir.

5) Kurutulan ürünlerin tazeye göre, incelenen kimyasal özellikleri açısından en uygun sıcaklığın $65{ }^{\circ} \mathrm{C}$ olduğu bulunmuştur.

Sonuç olarak armut posası konvektif bir kurutucu ile kurutulacaksa $65{ }^{\circ} \mathrm{C}$ kurutma havası sıcaklığının seçilmesi önerilmektedir.

\section{KAYNAKÇA}

[1].A.N. Da Silva, C.J.S. Dos Reis, F.M. Botelho, M.N. De Moraes, J.T. De Faria, T. Da Conceiçao, M. Bezerra, M.A.
Martins, and S.A.M. De Oliveira, "Pear drying Thermodynamics studies and coeefficients of convective heat and mass transfer". International Journal Food Engineering 9(4): 365-374, 2013.

[2].I. Doymaz and O. Ismail, "Experimental characterization and modelling of drying of pear slices". Food Sci Biotechnol, 21(5):1377-1381, 2012.

[3].A. Soylu, "Ilıman İklim Meyveleri - II", Uludağ Üniversitesi, Ziraat Fakültesi, Ders Notları, Bursa, 2003.

[4].A. Itai, "Pear Genome Mapping and Moleculer Breeding in Plants". Fruit and Nuts, 4:157-170, 2007.

[5].M. Pektaş, "Hasat Öncesi Bazı Bitki Büyümeyi Düzenleyici Madde (BBDM) uygulamalarının Akça ve B.P. Morettını Armutlarında (Pyrus communis L.) Meyve Kalitesi Üzerine Etkileri”. Süleyman Demirel Üniversitesi, Fen Bilimleri Enstitüsü, Yüksek Lisans Tezi, Isparta, 2009.

[6].A.G. Özaydın ve S. Özçelik, "Farklı Kurutma Koşullarının Bazı Önemli Armut Çeşitlerinin Mikrobiyolojik Kalitesi Üzerine Etkilerinin Araştırılması”. Meyve Bilimi, ISSN: 2148-0036, 3 (1), 37-44, 2016.

[7].J. Chen, Z. Wang, J. Wu, Q. Wang and X. Hu, "Chemical compositional characterization of eight pear cultivars grown in China”. Food Chem, 104 (1): 268-275, 2007.

[8].J. Salta, A. Martins, R.G. Santos, N.R. Neng, J.M.F. Nogueira, J. Justino and A.P. Rauter, "Phenolic composition and antioxidant activity of Rocha pear and other pear cultivars - A comparative study". Journal Functional Foods, 2(2): 153-157, 2010.

[9].S.C.R.V.L. Santos, R.P.F. Guine and A. Barros, "Effect of drying temperatures on the phenolic composition and antioxidant activity of pears of Rocha variety (Pyrus communis L.)". Food Measur, 8: 105-112, 2014.

[10].R.P.F. Guine, M.J. Barroca, F.J. Gonçalves, M. Alves, S. Oliveira and P.M.R. Correia, "Effect of drying on total phenolic compounds, antioxidant activity, and kinetics decay in pears". Int J Fruit Sci, 15: 173-186, 2015.

[11].F.A. Juhaimi, N. Uslu, M.M. Özcan, E.F.E. Babiker and K. Ghafoor, "Effect of drying on antioxidant activity, total phenol and mineral contents of pear fruits". Journal of Food Safety and Food Quality, 67 (5),113-148, 2016.

[12].S. Kaur, B.C. Sarkar and H.K. Sharma, "Optimization of enzymatic hydrolysis pre-treatment conditions for enhanced juice recovery from guava fruit using response surface methodology". Food Bioprocess Technology, 2(1): 96-100, 2009.

[13].N. Kumar, B.C. Sarkar and H.K. Sharma, "Effect of air velocity on kinetics of thin layer carrot pomace drying". Food Science and Technology International, 17(5), 459-469, 2011. 
[14].P.S. Pisalkar, N.K. Jain and S.K. Jain, "Osmo-air drying of aloe vera gel cubes". Journal of food science and technology-mysore 48-2, 183-189, 2011.

[15].G.E.G. Moreira, M.G.M. Costa, A.C.R. De Souza, E.S. De Brito, M.F.D. Medeiros and H.M.C. De Azeredo, "Physical properties of spray dried acerola pomace extract as affected by temperature and drying aids". LWT - Food Sci Tech, 42: 641-645, 2009.

[16].U. Boylu, "Üzüm Posası Silajlarında Farklı Katkı Maddesi Kullanımının Fermentasyon Gelişimi Ve Bazı Mikrobiyolojik Paremetreler Üzerine Etkileri”. Fen bilimleri Ensititüsü, Zootekni Anabilim Dalı, Yüksek lisans Tezi, Tekirdağ, 2009.

[17].P. Çilem, "Sosis Üretiminde Kurutulmuş Kayısı Posası Kullanımının Araştırılması". Ege Üniversistesi, Fen bilimleri Enstitüsü, Gıda Mühendisliği Anabilim dalı Yüksek lisans tezi, İzmir, 2006.

[18].F. Göğüş and M. Maskan, "Air drying characteristics of solid waste (pomace) of olive oil processing". Journal of Food Engineering 72, 378-382, 2006.

[19].M. Smail, "Drying kinetics of olive pomace in a fluidized bed dryer". Energy Conversion and Management, 5,2 1644-1649, 2011.

[20].M.Y. Yalçınkaya, E. Baytok ve M.A. Yörük, "Değişik Meyve Posası Silajlarının Bazı Fiziksel ve Kimyasal Özellikleri*”. Erciyes Üniversitesi Veteriner Fakülte Dergisi, 9(2) 95-106, 2012.

[21].A. Yağcıoglu, Tarımsal Ürünleri Kurutma Tekniği. Ege Üniversitesi Ziraat Fakültesi yayınları No: 536. Bornova, İzmir, 1999.

[22].Ş. Karagül ve M. Taşova, "Determination of the Optimum Drying Method in Terms of Color Value of Cress (Lepidium sativum L.) Leaves Dried by Microwave Method with Pre-treatment and without Pre-treatment". Journal of New Results in Science, 6 (2), 24-31, 2017.

[23].H. Polatcı ve M. Taşova, "Sıcaklık Kontrollü Mikrodalga Kurutma Yönteminin Alıç (Crataegusspp. L.) Meyvesinin Kuruma Karakteristikleri ve Renk Değerleri Üzerine Etkisi”. Türk Tarım - Gıda Bilim ve Teknoloji Dergisi, 5(10): 1130-1135, 2017.

[24].M.K. Krokida, C.T. Kiranoudis, Z.B. Maroulis and D. Marinos Kouris, "Effect of pretreatment on color of dehydrated products". Drying Technology, 18(6), 12391250, 2000.

[25].G. Adiletta, G. Iannone, P. Russo, G. Patimo, S. De Pasquale and M. Di Matteo, "Moisture migration by magnetic resonance imaging during eggplant drying: A preliminary study". International Journal of Food Science and Technology, 49, 2602-2609, 2014.

[26].R.G. McGuire, "Reporting of objective color measurements". HortScience, 27, 1254 - 1255, 1992.
[27].J. Lopez, A. Vega Galvez, M.J. Torres, R. Lemus Mondaca, I. Quispe Fuentes, and K. Di Scala, "Effect of dehydration temperature on physico-chemical properties and antioxidant capacity of goldenberry (Physalis peruviana L.)". Chılean Journal Of Agricultural Research 73(3), 293 300, 2013.

[28].M.T. Çakır, “Güneş Enerjisinden Yararlanarak Tarım Ürünlerinin Kurutulması".

Gazi Mühendislik Bilimleri Dergisi, 1(1), 41-56, 2015.

[29].A. Vega Galvez, K. Ah Hen, M. Chacana, J. Vergara, J. Martinez Monzo, P. Garcia Segovia, R. Lemus Mondaca, and K. Di Scala, "Effect of temperature and air velocity on drying kinetics, antioxidant capacityi total phenolic content, colour, texture and microtructure of apple (var. Granny Smith) slices". Food Chemistry, 132, 51-59, 2012.

[30].M. Taşova ve M. Güzel, "İstanbul Çeşidi Vişnenin (Prunus cerasus L.) Fiziko-Mekanik Özellikleri İle Renk Değerlerinin Belirlenmesi”. Gaziosmanpaşa Bilimsel Araştırma Dergisi, 6, Özel sayı, 1130-1135, 2017.

[31].E. Plou, A. Lopez-Malo, G.V. Barbosa-Canovas, J. Welti-Chanes and B.G. Swanson, "Polyphenoloxidase activitiy and color of blanced and high hydrostatic pressure treated banana puree". Journal of Food Science, 64, 42-45, 1999.

[32].İ. Karaçalı, "Bahçe Ürünlerinin Muhafazası ve Pazarlanması”. 413s, Bornova- İzmir, 1990.

[33].B. Cemeroğlu, "Meyve ve Sebze İşleme Endüstrisinde Temel Analiz Metodları". Biltav Yay. 381s. Ankara, 1992.

[34].F. Açıkgöz Eryılmaz, "Kuzukulağı (Rumex Acetosa L.) Bitkisinin Farklı Kurutma Yöntemleri Kullanılarak Kurutulması Ve Kalite Özelliklerinin Belirlenmesi”. Namık Kemal Üniversitesi, Bilimsel Araştırma Projesi, (Proje No: NKUBAP.00.MB.AR.15.01), 2015.

[35].H. Polatci and S. Tarhan, "The Effect of Different Drying Methods on Drying and Quality of Reyhan (Ocimum Basilicum) Plant. GOI. Journal of Agricultural Faculty, 26 (1), 61-70, 2009.

[36].M. Taşova, "Düşük ve Yüksek Sıcaklıklarda Kurutulan Patlıcan (Solanum melongena L.) Dilimlerinin Kurutma Kinetiği ve Renk Değerleri Açısından En Uygun Kurutma Sıcaklığının Belirlenmesi”. Kafkas Üniversitesi Fen Bilimleri Enstitüsü Dergisi, 2018. 11(2), Syf: 84-93, 2018.

[37].G. Ergüneş ve M. Taşova, "Kabin kurutucuda kurutulan kuşburnu (Rosa canina L.) meyvesinin kuruma performans1, efektif difüzyon ve aktivasyon enerjisi değerlerinin belirlenmesi". Akademik Ziraat Dergisi, Cilt 7, Sayı 1, Syf: 75-82, 2018.

[38]. H. Polatcı, M. Taşova, O. Sarçoğlu ve O. Taşkın, "Şeftali (Prunus persica L.) Posasının Farklı Sicaklıklarda Kuruma Parametrelerin Belirlenmesi". Tarım Makinaları Bilimi Dergisi, 14 (3), Syf: 149-156, 2018. 